\title{
Microfluidization-Driven Changes in Some Physicochemical Characteristics, Metal/Mineral Composition, and Sensory Attributes of Sugarcane Juice
}

\author{
Ayon Tarafdar $\mathbb{D}^{1,2}$ and Barjinder Pal Kaur $\mathbb{D}^{1}$ \\ ${ }^{1}$ Department of Food Engineering, National Institute of Food Technology Entrepreneurship and Management, Kundlu, \\ Sonipat 131028, Haryana, India \\ ${ }^{2}$ Livestock Production and Management Section, ICAR-Indian Veterinary Research Institute, Izatnagar, Bareilly 243122, \\ Uttar Pradesh, India
}

Correspondence should be addressed to Barjinder Pal Kaur; barjinderpkaur@gmail.com

Received 26 August 2021; Accepted 22 November 2021; Published 8 December 2021

Academic Editor: Muhammad Imran

Copyright (C) 2021 Ayon Tarafdar and Barjinder Pal Kaur. This is an open access article distributed under the Creative Commons Attribution License, which permits unrestricted use, distribution, and reproduction in any medium, provided the original work is properly cited.

\begin{abstract}
This work evaluated the effect of microfluidization at different pressure $(50,100,150$, and $200 \mathrm{MPa})$-cycle $(1,3,5,7)$ combinations on the physicochemical (total soluble solids, titratable acidity, $\mathrm{pH}$, and electrical conductivity), sensory, and metal/mineral composition of sugarcane juice which was previously unexplored. Juice extracted from blanched sugarcane stems (var Co 0238) was microfluidized, and the analysis for different parameters was conducted using standard protocols. The mineral $/ \mathrm{metal}$ composition was determined using ICP-OES following a wet digestion method. Results showed that TSS decreased from 18.88 ${ }^{\circ}$ Brix to a range of $10.15-15.7^{\circ}$ Brix with the former (lower value) being due to the release of insoluble matter after microfluidization which was further solubilised at higher processing cycles (as in the latter). The $\mathrm{pH}$ did not vary significantly as compared to control and was in the range of 5.2-5.7. However, a decrease in titratable acidity $(0.1-0.26 \%)$ was found as compared to control $(0.26 \%)$. The electrical conductivity of microfluidized sugarcane juice varied from 4.45 to $5.12 \mathrm{mS}$ as compared to $4.95 \mathrm{mS}$ for control. Metal/mineral analysis showed rich reserves of magnesium, phosphorus, potassium, and calcium in sugarcane juice which degraded after microfluidization perhaps due to filtration effect caused by the micropore in the interaction chamber of the microfluidizer. The sensory score showed acceptability of the juice after microfluidization (overall acceptability $\sim 7$ ).
\end{abstract}

\section{Introduction}

Microfluidization is an emerging liquid and semisolid food processing technique that has gained popularity in the food sector. It is a high-pressure processing technology that works on the principle of high-shear force generation with occasional cavitation through a microchannel of fixed geometry. Microfluidization is now extensively used for emulsification, particle size reduction, enzymatic inactivation, and microbial destruction [1-3]. The effect of microfluidization on the quality characteristics of different juices has been investigated that includes mango and goji juice [4], yam juice [5], jujube juice[6], peach juice [7], seabuckthorn juice [4], Ottoman strawberry juice [8], and carrot juice [9], among others. Due to its tremendous potential for juice preservation, it is now being considered as a viable option for beverage processing unit operations.

Sugarcane juice is another plant-derived beverage which is relished in tropical climates as a thirst-quenching drink with numerous health benefits. However, sugarcanes are not available throughout the year, and its juice is very difficult to process and preserve due to its high sugar composition which promotes yeast and bacterial growth. Fortunately, the effect of microfluidization on the quality characteristics of sugarcane juice has been investigated in previous studies [10-12] which helped establish the fact that the technology can be used effectively for juice preservation to some extent. However, the effect of microfluidization on the 
physicochemical characteristics of sugarcane juice such as titratable acidity, $\mathrm{pH}$, electrical conductivity, and metal/ mineral composition has not been reported yet. Moreover, the sensory attributes of sugarcane juice as affected by microfluidization has also not been evaluated, to the best of our knowledge. Therefore, this work aims to analyze the effect of microfluidization on the physicochemical, metal/ mineral, and sensory characteristics of sugarcane juice over a wide range of processing conditions (pressure/cycle combinations) to fill the identified knowledge gap.

\section{Materials and Methods}

2.1. Material Procurement and Processing. Freshly harvested mature sugarcane stems (var. Co 0238) were procured from a local farm of Kashipur $\left(29.2115^{\circ} \mathrm{N}, 78.9692^{\circ} \mathrm{E}\right)$, Uttarakhand (India). Stems of diameter $2.5 \pm 0.9 \mathrm{~cm}$ were washed and cut into $0.45 \mathrm{~m}$ long pieces. The cut pieces were then blanched in hot water at $95^{\circ} \mathrm{C}$ for $5 \mathrm{~min}$. After blanching, the stems were retrieved from the water bath and immediately cooled under running water $\left(25 \pm 3^{\circ} \mathrm{C}\right)$ for $2-3 \mathrm{~min}$. The excess water on the stems was wiped clean using a piece of cotton cloth, and the stems were then kept for 30-60 min at room temperature prior to juice extraction. A twin roll mechanical crusher was used for juice extraction. The crusher was cleaned with distilled water and wiped with a sterilized cotton cloth prior to the extraction process. The extracted juice was filtered using two-layered muslin cloth to remove particulate matter. The collected juice was kept under refrigeration and processed within 10-15 min.
Sugarcane juice was processed using a laboratory-scale microfluidizer equipped with a Y-type diamond interaction chamber with a $75 \mu \mathrm{m}$ channel (M 110-P, Microfluidics, Corporation, Newton, MA, USA). Microfluidization pressure was varied as $50,100,150$, and $200 \mathrm{MPa}$, while the number of microfluidization cycles was varied as $1,3,5$, and 7. Untreated juice was taken as control.

2.2. Determination of Total Soluble Solids. Total soluble solid (TSS) content was measured using a digital refractometer (Model RX-7000i, Atago, Japan). The sample chamber of the equipment was washed with Milli-Q water and wiped clean before analysis. The equipment was calibrated with Milli-Q water at $25^{\circ} \mathrm{C}$. Sugarcane juice (2-3 drops) was then placed in the sample chamber, and the results were recorded in oBrix. The sample chamber was cleaned with Milli-Q water between consecutive sample measurements to ensure that there was no trace of the earlier sample.

2.3. Titratable Acidity and $p H$. Titratable acidity was determined using the method of Singh et al. (2012) with minor modifications [13]. Twenty millilitres of diluted sugarcane juice sample (1:10 with Milli-Q water) was reacted with $0.1 \mathrm{~N} \mathrm{NaOH}$ in the presence of phenolphthalein indicator (1-2 drops). End point was identified by the occurrence of a light pink color in the reaction mixture with the addition of base. The percentage acidity was expressed in citric acid equivalence as

$$
\% \text { titratable acidity }=\frac{\text { Volume of } \mathrm{NaOH} \text { used } \times \text { normality of } \mathrm{NaOH} \times \text { equivalent weight of citric acid }}{1000 \times \text { volume of sample titrated }} \times 100
$$

The $\mathrm{pH}$ of the control and microfluidized sample was determined using a calibrated digital $\mathrm{pH}$ meter (CyberScan EUTECH, Thermo Fischer Scientific, India) with an uncertainty of \pm 0.1 . The $\mathrm{pH}$ meter was washed with Milli-Q water and wiped clean before and after sample measurement.

2.4. Determination of Electrical Conductivity. Electrical conductivity was measured using a portable water analyzer (Model 371, Systronics, India) equipped with a $1.0 \mathrm{~K}$ probe (range $0.01-100 \mathrm{mS} / \mathrm{cm}$ ). The equipment was calibrated using $\mathrm{KCl}$ solutions of $0.1 \mathrm{M}(12.88 \mathrm{mS} / \mathrm{cm}), 0.01 \mathrm{M}(1.41 \mathrm{mS} /$ $\mathrm{cm})$, and $0.001 \mathrm{M}(0.146 \mathrm{mS} / \mathrm{cm})$ concentrations prior to measurements. All measurements were carried out at $25^{\circ} \mathrm{C}$. Results were expressed in milli Siemens per centimeter (or $\mathrm{mS} / \mathrm{cm})$.

2.5. Determination of Metal/Mineral Composition by Inductively Coupled Plasma-Optical Emission Spectroscopy (ICP$O E S)$. Sugarcane juice samples for metal/mineral analysis were prepared using the wet digestion method [14] with minor modifications [15]. Approximately $0.4-0.5 \mathrm{~g}$ of sample was taken in a $50 \mathrm{~mL}$ beaker. $1 \mathrm{~mL}$ of hydrogen peroxide was added to the sample for oxidation. The sample was digested using $5 \mathrm{~mL}$ of concentrated nitric acid (69\%) with constant heating at $70^{\circ} \mathrm{C}$ in a water bath. Digestion was continued for 1.5-2 $\mathrm{h}$ till attainment of a pale yellow color. The digested sample was transferred to a $50 \mathrm{~mL}$ volumetric flask, and the volume was adjusted to $50 \mathrm{~mL}$ using Milli-Q water. Metal/ mineral composition in sugarcane juice was determined using a Perkin Elmer ICP-OES (Optima 7000 DV, USA). A multielemental standard was used for analysis of metals and minerals. The equipment was calibrated using different concentrations of the standard $(5,10,25,50$, and $100 \mathrm{ppb})$ in $5 \% \mathrm{HNO}_{3}$. Reference blank was taken as diluted $\mathrm{HNO}_{3}(5 \%)$. Analysis was carried out in triplicates. Results were expressed as the elemental mineral present in $\mathrm{mg} / \mathrm{mL}$ of sugarcane juice.

2.6. Sensory Evaluation of Microfluidized Sugarcane Juice. Sensory evaluation was conducted using a 9-point hedonic scale with a panel of 29 semitrained members (13 males +16 females) comprising faculty members and students of 


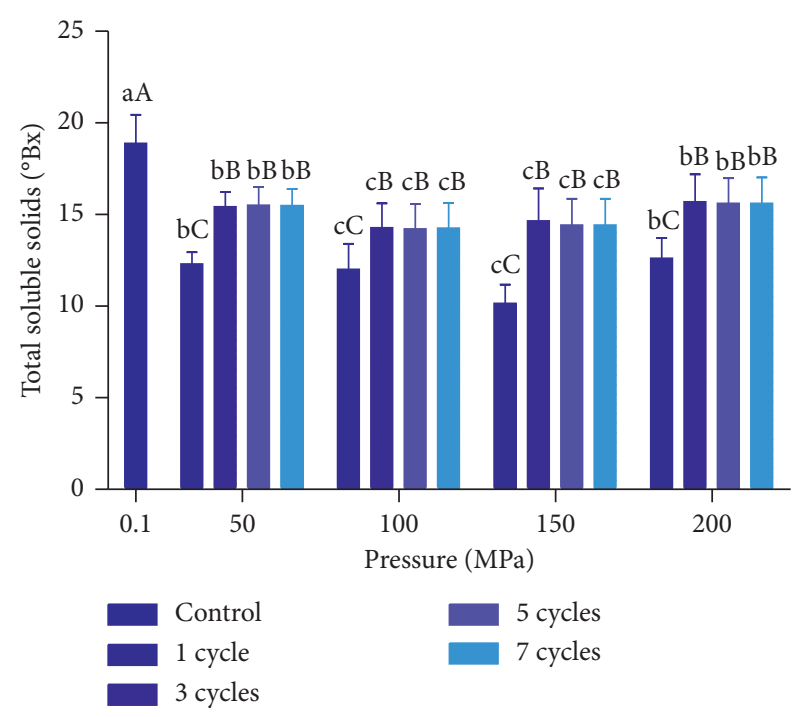

Figure 1: Effect on total soluble solids with microfluidization.

NIFTEM, Sonipat (India). The panelists were in the age group of 17-35. The scorecard was prepared and given to each panel member to evaluate the attributes of the fresh and processed juice in terms of color, aroma, sweetness, taste, and overall acceptability. The panel members were seated away from each other under constant ambient conditions. They were asked to rinse their mouth with water between consecutive samples. It was also ensured that no panel member was suffering from any cold or fever or was, in any way, organoleptically challenged.

2.7. Statistical Analysis. All experiments were performed in triplicates, and the analysis of dependent parameters was conducted at least in duplicates. The results were expressed as mean \pm standard deviation. ANOVA and Duncan's multiple-range test (post hoc analysis) were conducted in SPSS v.20 software (IBM, USA) at 5\% significance level.

\section{Results and Discussion}

3.1. Effect on TSS. The TSS of control was estimated as $18.88 \pm 1.58^{\circ} \mathrm{Brix}$ which was concomitant to that of reported literatures. A significant decrease in TSS was observed after microfluidization $(p<0.05)$ that varied in the range of $10.16 \pm 1.03$ to $15.71 \pm 1.49^{\circ}$ Brix. Denaturation of enzymes in the juice as a result of pressure treatment could be associated with the decrease in TSS [8].

The reduction in TSS with microfluidization is in contradiction to the results observed during high-pressure processing of sugarcane juice,probably due to the nature of pressure augmentation in the two technologies. In the first cycle of processing, lower TSS was observed at all microfluidization pressures (Figure 1) which increased at higher processing cycles. This change could be due to higher extent of particle size reduction and release of any insoluble solids from the particles for multiple shearing actions. Increasing the number of cycles to three, five, and seven increased the TSS, but there was no significant difference in TSS within these cycles $(p>0.05)$. This shows that three passes is sufficient for complete mass transfer from the juice particles and further solubilisation in the surrounding medium.

3.2. Effect on $\mathrm{pH}$ and Titratable Acidity. The $\mathrm{pH}$ of control was determined as 5.55 at $25^{\circ} \mathrm{C}$ and did not vary significantly with microfluidization pressure and cycles $(p>0.05)$. The $\mathrm{pH}$ of the microfluidized sample was observed in the range of 5.21-5.79 (Figure 2(a)). In contrast, titratable acidity varied with both microfluidization pressure and the number of cycles $(p<0.05)$. The percentage titratable acidity for control was observed as $0.26 \%$. After microfluidization, the titratable acidity varied in the range of $0.10-0.26 \%$ with no specific trend in data (Figure 2(b)). At the first cycle, an increasing-decreasing trend was observed, while at the third cycle, no significant change in acidity was observed till $100 \mathrm{MPa}$ pressure with highly reduced acidity at $150 \mathrm{MPa}$ pressure.

At the second cycle of processing, there was slightly increased acidity at pressures of 150 and $200 \mathrm{MPa}$. At the third cycle, the acidity at $150 \mathrm{MPa}$ decreased significantly following which there was an abrupt increase at $200 \mathrm{MPa}$. At the fourth cycle, the acidity increased upto $150 \mathrm{MPa}$ pressure and then decreased again at $200 \mathrm{MPa}$. Overall, the pressure/ cycle combination of $150 \mathrm{MPa} / 7$ cycles and $200 \mathrm{MPa} / 3$ cycles was able to maintain the natural acidity conditions of sugarcane juice.

3.3. Effect on Electrical Conductivity. The electrical conductivity (EC) of control was observed as $4.95 \pm 0.20 \mathrm{mS}$ and varied in the range of $4.45 \pm 0.34$ to $5.12 \pm 0.10 \mathrm{mS}$ with microfluidization (Figure 3). EC of the microfluidized sugarcane juice varied significantly with pressure $(p<0.05)$ but not with the number of cycles $(p>0.05)$. At pressures higher than $100 \mathrm{MPa}$, the electrical conductivity was observed to be relatively higher and comparable to that of control. Formation of ions in sugarcane juice due to high pressure and cavitation could lead to an increase in EC.

3.4. Effect on Metal/Mineral Composition. Control and microfluidized samples exhibited substantial amounts of magnesium, phosphorus, potassium, and calcium with trace amounts $(<0.05 \mathrm{mg} / \mathrm{mL})$ of lead and manganese (Table 1$)$. The presence of lead could be due to heavy-metal-contaminated irrigation water used for cultivation of the sugarcane crop. Degradation of metal/mineral content was observed with microfluidization.

The maximum degradation of $42.85 \%$ in $\mathrm{Mg}, 38.69 \%$ in $\mathrm{P}, 18.99 \%$ in $\mathrm{K}, 58.83 \%$ in $\mathrm{Ca}$, and $39.13 \%$ in $\mathrm{Mn}$ was observed with microfluidization of sugarcane juice. From the results, it can also be seen that calcium and magnesium are the most susceptible minerals to high-pressure microfluidization. The reduction in minerals in general could be due to the pore size of the microchannel in the microfluidizer that could have restricted the minerals from moving out. There was also a $46.42 \%$ reduction in $\mathrm{Pb}$ content 


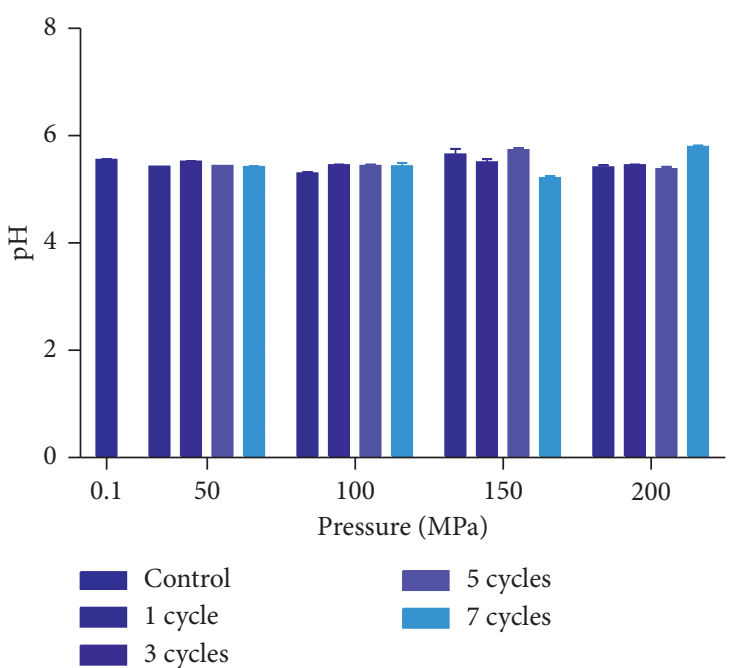

(a)

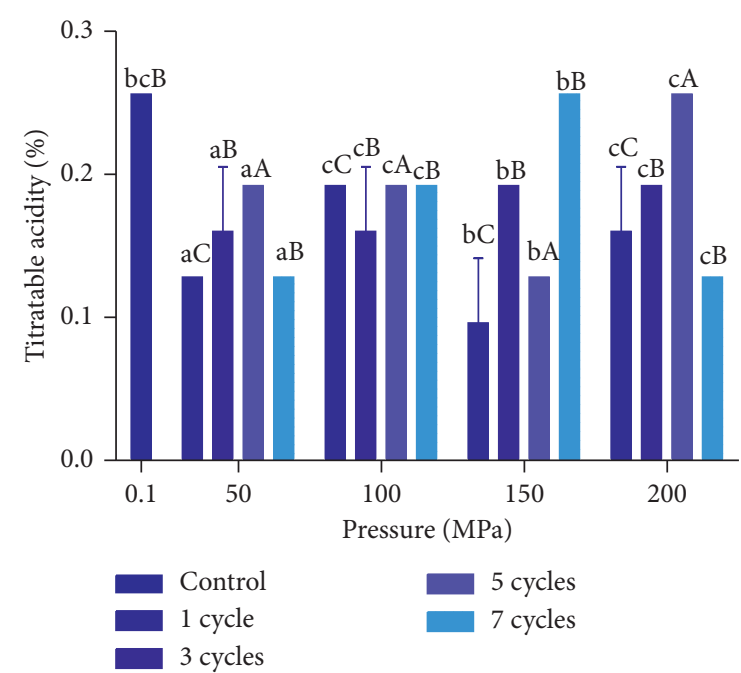

(b)

FIGURE 2: Effect of microfluidization on (a) pH and (b) titratable acidity. Post hoc test was not applied on pH values as ANOVA was found nonsignificant.

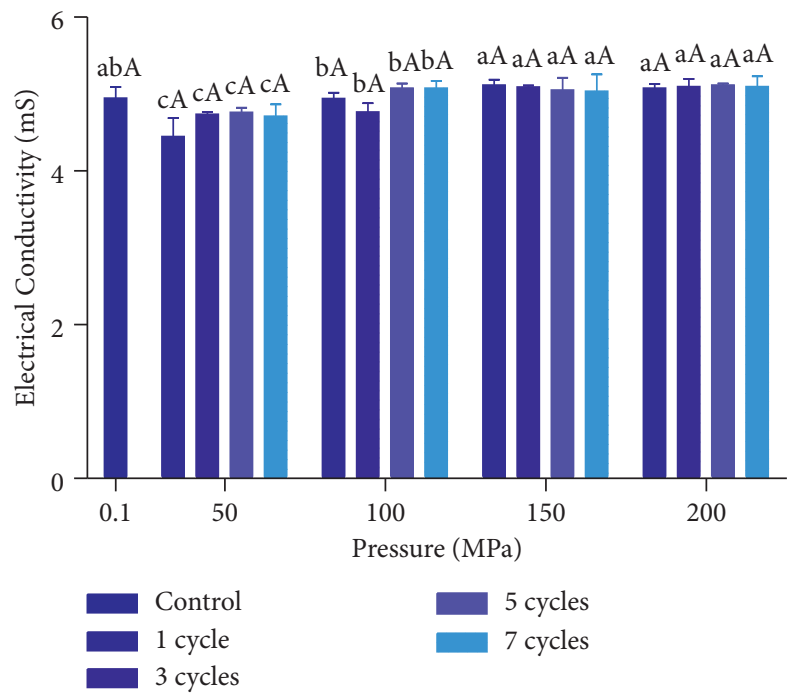

Figure 3: Electrical conductivity of control and microfluidized sugarcane juice. Small-case letters represent the effect of pressure, while capital-case letters represent the effect of passes. Datasets with different letters differ significantly at 5\% level of significance by Duncan's multiple comparison test.

which shows that microfluidization could have applications in heavy-metal removal.

3.5. Analysis of Sensory Characteristics. The sensory profile was judged on the basis of color, aroma, sweetness, taste, and overall acceptability of the control and microfluidized sugarcane juice (Table 2). The color of the control was scored as 7.2, while the score of microfluidized juice ranged from 6.8-7.7 indicating color retention in sugarcane juice after processing, from a subjective viewpoint. The aroma score of control was 7.4 , while the score of microfluidized juice varied from 6.7-7.8. The aroma score was lower for all processing conditions except at $150 \mathrm{MPa} / 1$ cycle showing retention of aroma at this processing condition. The sweetness of control was scored as 7.1 and received a slightly higher score for the processed juice at $100 \mathrm{MPa} / 1$ cycle, $150 \mathrm{MPa} / 1$ cycle, and $150 \mathrm{MPa} / 7$ cycle. Higher sweetness could be an indication of conversion of sucrose to reducing sugars such as fructose and glucose [12]. The taste score of sugarcane juice varied from 6.8 to 7.4 with 7.2 for control. Although the highest score was observed at $200 \mathrm{MPa} / 1$ cycle; the processing condition showed lower scores for other sensory characteristics. Taking into account higher color, aroma, sweetness, and overall acceptability score of sugarcane juice processed at $150 \mathrm{MPa} / 1$ cycle, it could be considered a viable processing condition from a sensory standpoint. 
TABLE 1: Metal and mineral composition (in $\mathrm{mg} / \mathrm{L}$ ) of control and microfluidization sugarcane juice.

\begin{tabular}{lccccr}
\hline Processing conditions & $\mathrm{Mg}$ & $\mathrm{P}$ & $\mathrm{K}$ & $\mathrm{Ca}$ & $\mathrm{Pb}$ \\
\hline Control & 2.728 & 1.274 & 2.395 & 2.009 & 0.028 \\
$50 / 1$ cycle & 2.422 & 1.213 & 2.234 & 1.929 & 0.012 \\
$50 / 3$ cycles & 1.955 & 1.131 & 2.267 & 1.559 & 0.019 \\
$50 / 5$ cycles & 1.559 & 0.781 & 2.429 & 0.827 & 0.022 \\
$50 / 7$ cycles & 1.616 & 0.887 & 2.195 & 1.102 & 0.020 \\
$100 / 1$ cycle & 1.857 & 0.937 & 2.361 & 1.172 & 0.016 \\
$100 / 3$ cycles & 2.001 & 1.040 & 2.111 & 1.263 & 0.018 \\
$100 / 5$ cycles & 2.214 & 1.043 & 2.342 & 1.424 & 0.017 \\
$100 / 7$ cycles & 2.209 & 1.033 & 2.392 & 1.601 & 0.017 \\
$150 / 1$ cycle & 2.340 & 1.108 & 2.354 & 1.616 & 0.017 \\
$150 / 3$ cycles & 2.191 & 1.117 & 2.045 & 1.551 & 0.016 \\
$150 / 5$ cycles & 2.060 & 0.984 & 1.949 & 1.310 & 0.014 \\
$150 / 7$ cycles & 1.987 & 1.123 & 1.940 & 1.878 & 0.018 \\
$200 / 1$ cycle & 2.339 & 1.245 & 2.303 & 2.013 & 0.018 \\
$200 / 3$ cycles & 2.212 & 1.058 & 2.314 & 1.733 & 0.020 \\
$200 / 5$ cycles & 2.133 & 1.209 & 2.270 & 0.019 \\
$200 / 7$ cycles & 2.200 & 1.216 & 2.011 & 0.019 \\
\hline
\end{tabular}

TABLE 2: Sensory characteristics of control and microfluidized sugarcane juice.

\begin{tabular}{|c|c|c|c|c|c|}
\hline Processing condition & Color & Aroma & Sweetness & Taste & Overall acceptability \\
\hline Control & $7.2 \pm 0.9$ & $7.4 \pm 0.9$ & $7.1 \pm 1.2$ & $7.2 \pm 0.9$ & $7.2 \pm 1.2$ \\
\hline $50 \mathrm{MPa} / 1$ cycle & $7.3 \pm 1.0$ & $7.1 \pm 1.1$ & $6.9 \pm 1.1$ & $7.2 \pm 1.0$ & $7.1 \pm 0.9$ \\
\hline $50 \mathrm{MPa} / 3$ cycles & $7.2 \pm 1.0$ & $7.1 \pm 0.9$ & $6.8 \pm 1.1$ & $7.0 \pm 1.0$ & $6.9 \pm 0.9$ \\
\hline $50 \mathrm{MPa} / 5$ cycles & $6.7 \pm 1.5$ & $7.2 \pm 1.1$ & $7.0 \pm 1.0$ & $7.1 \pm 0.8$ & $7.1 \pm 0.9$ \\
\hline $50 \mathrm{MPa} / 7$ cycles & $6.9 \pm 1.0$ & $6.7 \pm 0.9$ & $6.7 \pm 1.3$ & $6.8 \pm 0.9$ & $6.8 \pm 1.0$ \\
\hline $100 \mathrm{MPa} / 1$ cycle & $7.3 \pm 0.9$ & $7.2 \pm 0.9$ & $7.4 \pm 0.9^{*}$ & $7.3 \pm 0.9$ & $7.1 \pm 0.8$ \\
\hline $100 \mathrm{MPa} / 3$ cycles & $7.2 \pm 1.1$ & $7.0 \pm 0.8$ & $6.9 \pm 1.2$ & $7.1 \pm 0.9$ & $6.9 \pm 1.0$ \\
\hline $100 \mathrm{MPa} / 5$ cycles & $7.0 \pm 0.9$ & $6.8 \pm 1.0$ & $6.9 \pm 1.0$ & $7.0 \pm 0.9$ & $6.9 \pm 0.9$ \\
\hline $100 \mathrm{MPa} / 7$ cycles & $6.9 \pm 1.3$ & $6.8 \pm 1.3$ & $7.1 \pm 1.0$ & $6.9 \pm 0.8$ & $6.9 \pm 1.1$ \\
\hline $150 \mathrm{MPa} / 1$ cycle & $7.7 \pm 0.9^{*}$ & $7.8 \pm 0.8^{*}$ & $7.4 \pm 0.8^{*}$ & $7.3 \pm 0.9$ & $7.4 \pm 0.8^{*}$ \\
\hline $150 \mathrm{MPa} / 3$ cycles & $7.1 \pm 1.1$ & $7.2 \pm 0.9$ & $6.7 \pm 1.1$ & $6.9 \pm 1.3$ & $6.6 \pm 1.2$ \\
\hline $150 \mathrm{MPa} / 5$ cycles & $7.1 \pm 1.2$ & $7.1 \pm 1.3$ & $6.9 \pm 1.3$ & $7.3 \pm 0.9$ & $7.2 \pm 1.1$ \\
\hline $150 \mathrm{MPa} / 7$ cycles & $6.9 \pm 1.2$ & $7.3 \pm 1.2$ & $7.2 \pm 0.7$ & $6.9 \pm 1.3$ & $6.9 \pm 1.5$ \\
\hline $200 \mathrm{MPa} / 1$ cycle & $7.1 \pm 1.1$ & $7.3 \pm 1.1$ & $7.0 \pm 1.0$ & $7.4 \pm 0.9^{*}$ & $7.1 \pm 1.0$ \\
\hline $200 \mathrm{MPa} / 3$ cycles & $6.9 \pm 1.5$ & $6.8 \pm 1.4$ & $7.1 \pm 1.4$ & $7.2 \pm 0.9$ & $6.9 \pm 1.6$ \\
\hline $200 \mathrm{MPa} / 5$ cycles & $7.1 \pm 1.3$ & $6.9 \pm 1.0$ & $6.7 \pm 0.8$ & $6.9 \pm 1.1$ & $6.9 \pm 1.5$ \\
\hline $200 \mathrm{MPa} / 7$ cycles & $6.8 \pm 1.1$ & $6.8 \pm 0.9$ & $6.5 \pm 1.2$ & $7.0 \pm 1.0$ & $6.4 \pm 1.3$ \\
\hline
\end{tabular}

${ }^{*}$ Highest value of each sensory parameter.

\section{Conclusions}

Microfluidization significantly influences the physicochemical characteristics of sugarcane juice with minimal effect on the sensory attributes. No significant effect was found on the $\mathrm{pH}$ which shows that $\mathrm{pH}$ adjustment of sugarcane juice for preservation may be accompanied with microfluidization. Based on the results, it can be inferred that pressures higher than $100 \mathrm{MPa}$ but lower than $200 \mathrm{MPa}$ could yield high-quality sugarcane juice with better nutritional properties. The influence of microfluidization on the functional properties of sugarcane juice through in vivo methods is warranted.

\section{Data Availability}

All data pertaining to this work are provided in the article.

\section{Conflicts of Interest}

The authors declare no conflicts of interest with respect to this work.

\section{Acknowledgments}

The authors thank the Vice-Chancellor of the National Institute of Food Technology Entrepreneurship and 
Management, Kundli, Sonipat for his support in conducting this work. The first author thanks UGC for providing senior research fellowship, letter no. F1-17.1/2017-18/RGNF-201718-SC-RAJ- 37149.

\section{References}

[1] K. Verma, A. Tarafdar, V. Mishra, N. Dilbaghi, K. K. Kondepudi, and P. C. Badgujar, "Nanoencapsulated curcumin emulsion utilizing milk cream as a potential vehicle by microfluidization: bioaccessibility, cytotoxicity and physico-functional properties," Food Research International, vol. 148, Article ID 110611, 2021.

[2] A. Tarafdar, B. P. Kaur, P. K. Nema, O. A. Babar, and D. Kumar, "Using a combined neural network-genetic algorithm approach for predicting the complex rheological characteristics of microfluidized sugarcane juice," Lebensmittel-Wissenschaft \& Technologie, vol. 123, Article ID 109058, 2020.

[3] A. Tarafdar and B. P. Kaur, "Sedimentation rate of microfluidized sugarcane juice," Lebensmittel-Wissenschaft \& Technologie, vol. 145, Article ID 111317, 2021.

[4] A. Abliz, J. Liu, L. Mao, F. Yuan, and Y. Gao, "Effect of dynamic high pressure microfluidization treatment on physical stability, microstructure and carotenoids release of sea buckthorn juice," Lebensmittel-Wissenschaft \& Technologie, vol. 135, Article ID 110277, 2021.

[5] X. J. Guo, W. Zong, G. Y. Zhao, L. H. Zhang, X. Y. Wang, and $\mathrm{S}$. H. Wu, "Effect of high pressure microfluidization (HPM) on the physical stability of yam juice," Science and Technology of Food Industry, vol. 37, no. 17, pp. 125-128, 2016.

[6] W. Zong, S. Wu, and S. Wang, "Effect of dynamic highpressure microfluidization processing on the nutritional components and antioxidant activity of Chinese jujube juice," International Journal of Food Engineering, vol. 4, no. 2, pp. 132-135, 2018.

[7] X. Wang, S. Wang, W. Wang et al., "Comparison of the effects of dynamic high-pressure microfluidization and conventional homogenization on the quality of peach juice," Journal of the Science of Food and Agriculture, vol. 99, no. 13, pp. 5994-6000, 2019.

[8] C. H. Karacam, S. Sahin, and M. H. Oztop, "Effect of high pressure homogenization (microfluidization) on the quality of Ottoman strawberry (F. Ananassa) juice," Lebensmittel-Wissenschaft und Technologie-Food Science and Technology, vol. 64, no. 2, pp. 932-937, 2015.

[9] T. K. Koley, J. Nishad, C. Kaur et al., "Effect of high-pressure microfluidization on nutritional quality of carrot (Daucus carota L.) juice," Journal of Food Science \& Technology, vol. 57, no. 2, pp. 1-10, 2020.

[10] G. Kohli, G. Jain, A. Bisht, A. Upadhyay, A. Kumar, and S. Dabir, "Effect of non-thermal hurdles in shelf life enhancement of sugarcane juice," Lebensmittel-Wissenschaft \& Technologie, vol. 112, Article ID 108233, 2019.

[11] A. Tarafdar, S. G. Nair, and B. Pal Kaur, "Identification of microfluidization processing conditions for quality retention of sugarcane juice using genetic algorithm," Food and Bioprocess Technology, vol. 12, no. 11, pp. 1874-1886, 2019.

[12] A. Tarafdar, Y. Kumar, B. P. Kaur, and P. C. Badgujar, "Highpressure microfluidization of sugarcane juice: effect on total phenols, total flavonoids, antioxidant activity, and microbiological quality," Journal of Food Processing and Preservation, vol. 45, no. 5, Article ID e15428, 2021 b.
[13] R. K. Singh, A. Jha, C. K. Singh, and K. Singh, “Optimization of process and physico-chemical properties of ready-to-serve (rts) beverage of cane juice with curd," Sugar Tech, vol. 14, no. 4 , pp. 405-411, 2012.

[14] Please provide the complete publication details.

[15] H. Altundag and M. Tuzen, "Comparison of dry, wet and microwave digestion methods for the multi element determination in some dried fruit samples by ICP-OES," Food and Chemical Toxicology, vol. 49, no. 11, pp. 2800-2807, 2011. 